\title{
Imagens digitalizadas na avaliação do teste de tetrazólio em sementes de trigo
}

\author{
Emanueli Bastos Garcia ${ }^{1}$, Marizangela Rizzatti Ávila ${ }^{2}$, Nelson da Silva Fonseca Júnior ${ }^{2}$, Getulio Takashi \\ Nagashima². \\ ${ }^{1}$ Universidade Estadual de Londrina - UEL, Londrina, PR. ${ }^{2}$ Instituto de Desenvolvimento Rural do Paraná - IAPAR- \\ EMATER (IDR-Paraná), Londrina - PR. E-mail: ebastosgarcia@gmail.com
}

\section{Resumo}

O teste de tetrazólio com avaliação através de imagens digitalizadas pode ser uma alternativa para obtenção de resultados rápidos do potencial fisiológico de sementes. Nesse contexto, o objetivo do presente estudo foi avaliar a eficiência do teste de tetrazólio através da avaliação por análise de imagens digitalizadas na determinação da qualidade fisiológica de sementes de trigo. $O$ experimente o foi realizado com 22 lotes de sementes de trigo, submetidos à determinação do potencial fisiológico, incluindo o teste de tetrazólio avaliado por meio de análise de imagens digitalizadas. Para digitalização, após bissecção longitudinal, e coloração em solução de $0,075 \%$ de tetrazólio, as sementes foram agrupadas sobre vidro de scanner de mesa, armazenadas e classificadas em quatro classes de vigor. Os dados foram submetidos à análise de variância, com médias agrupadas pelo teste Scott-Knott, a 5\% de significância; também foi realizada análise dos coeficientes de correlação simples entre os resultados dos testes de tetrazólio e demais testes. A avaliação do teste de tetrazólio através da análise de imagens digitalizadas agrupou os lotes em três níveis de vigor. O método é eficiente na determinação de vigor e viabilidade de sementes de trigo, devido a possibilidade de ampliação das imagens que permite análise precisa das estruturas do eixo embrionário.

Palavras-chave: germinação; scanner; Triticum aestivum L.; vigor.

\section{Digitized images in the evaluation of the wheat seeds tetrazolium test}

\begin{abstract}
The tetrazolium test can be an alternative to obtain fast results of the physiological potential of wheat seeds. In this context, the objective of the present study was to evaluate the efficiency of the tetrazolium test through the evaluation by analysis of digitized images in the determination of the physiological quality of wheat seeds. The experiment was carried out with 22 lots of wheat seeds, submitted to the determination of the physiological potential, including the tetrazolium test evaluated by means of digitized image analysis. For digitization, after longitudinal bisection, and staining in $0.075 \%$ tetrazolium solution, the seeds were grouped on tabletop scanner glass, stored and classified into four vigor classes. Data were submitted to analysis of variance, with means grouped by the Scott-Knott test, at $5 \%$ of significance; we also performed an analysis of the simple correlation coefficients between tetrazolium test results and other tests. The evaluation of the tetrazolium test through the analysis of digitized images grouped the lots in three levels of vigor. The method is effective in determining the vigor and viability of wheat seeds, because the possibility of expanding the images that allows precise analysis of the embryonic axis structures.

Keywords: germination; scanner; Triticum aestivum L; vigor.
\end{abstract}

\section{Introdução}

A cultura do trigo ocupa a maior área cultivada do mundo devido à grande importância econômica e alimentar do cereal. Uma das características da cultura é de compensar a perda de plantas com o ajuste dos componentes de produtividade, porém a densidade de semeadura é um dos fatores mais decisivos para altos 
rendimentos (SILVEIRA et al., 2010). O estabelecimento adequado do estande inicial de plantas é reflexo das condições e tecnologias empregadas na semeadura e, principalmente, da qualidade fisiológica das sementes utilizadas (ABATl et al., 2017).

Para determinação da viabilidade, o teste de germinação é o teste padrão mais empregado em análise de sementes, permitindo obter-se o valor das sementes para semeadura. No entanto, não possibilita a estimativa do desempenho a campo sob condições adversas de ambiente (MAIA et al., 2011).

Nesse sentido, a fim de complementar as informações fornecidas pelo teste de germinação, os testes de vigor devem ser empregados dentro do controle de qualidade (MARCOS FILHO et al., 2009). Dentre eles, o tetrazólio tem destaque por gerar resultados rápidos, possibilitar a classificação de lotes em níveis de vigor e identificação dos possíveis agentes causais de danos nas sementes para algumas espécies como a soja (CARVALHO; NOVEMBRE, 2012).

Em sementes de Poaceae, a análise é atenciosamente voltada à observação da plúmula, área central do escutelo, coleóptilo, radícula e região das raízes seminais, que são vitais para o desenvolvimento (DIAS; BARROS, 1999). Para sementes de trigo, há recomendações padronizadas para realização do teste propostas pelas International Seed Testing Association (ISTA) e Regras para Análise de Sementes (RAS) (ISTA, 2008; BRASIL, 2009).

A fim de adaptar a metodologia do teste de tetrazólio para sementes de trigo, Carvalho et al. (2012) determinaram diferentes níveis de vigor, agrupando na classe 1: semente viável e vigorosa, classe 2: semente viável, mas não vigorosa, classe 3: semente não viável e na classe 4: semente morta com o embrião inteiramente descolorido.

Embora tenha as classes definidas, o teste ainda é pouco empregado em análise de sementes de trigo, sendo o tamanho reduzido das sementes e a necessidade de corte algumas das limitações para sua realização. Devido à importância do teste no controle de qualidade de sementes, há necessidade do desenvolvimento de alternativas que visem à diminuição do tempo total para realização e aprimoramento dos procedimentos.

Em sementes de Brachiaria brizantha, Custódio et al. (2012), observaram que análise de imagens digitalizada para interpretação do teste de tetrazólio, por meio de scanner, equivale à análise por observação em estéreo microscópio. A técnica mostrou-se eficiente na avaliação, além de garantir maior rapidez, facilidade, possibilidade de ampliação e armazenamento de imagens.

Nesse contexto, o objetivo deste estudo foi determinar a eficiência do teste de tetrazólio através da avaliação por análise de imagens digitalizadas para avaliação da qualidade fisiológica de sementes de trigo.

\section{Material e métodos}

O experimento foi conduzido no Laboratório de Análise de Sementes do Instituto Agronômico do Paraná (IAPAR), em Londrina-PR, utilizando 22 lotes de sementes de trigo de IPR Catuara, colhidas na safra 2015 e armazenadas em câmera fria até a condução do experimento. Para avaliação da qualidade fisiológica das sementes foram realizados os seguintes testes:

Germinação: realizado com oito repetições de 50 sementes, em papel toalha germitest ${ }^{\circ}$ umedecido com água destilada na proporção de 2,5 vezes a massa do papel seco. Os rolos de papel foram mantidos em germinador sob temperatura de $20{ }^{\circ} \mathrm{C}$, computando-se a porcentagem de plântulas normais aos quatro e oito dias após a instalação do teste (BRASIL, 2009).

Comprimento de plântulas: conduzido a partir da semeadura de quatro repetições de 20 sementes, no terço superior da folha de papel germitest ${ }^{\circ}$, umedecido com água destilada, na proporção de 2,5 vezes a massa do papel seco. Os rolos permaneceram por cinco dias em germinador, à temperatura de $20^{\circ} \mathrm{C}$, quando foi avaliado o comprimento das plântulas normais, com auxílio de uma régua e os resultados expressos em centímetros por plântula (NAKAGAWA, 1999).

Massa seca de plântulas: conduzido juntamente com o teste de comprimento de plântulas, onde a massa seca de plântulas normais foi mensurada em balança com precisão de 0,0001 g e os resultados expressos em mg por plântula (NAKAGAWA, 1999).

Índice de velocidade de germinação: obtido juntamente com o teste de germinação por meio de contagem diária de plântulas normais até o oitavo dia após instalação e estimado através da equação de Maguire (1962). 
Envelhecimento acelerado: instalado em caixa tipo "gerbox" adicionando $40 \mathrm{~mL}$ de água destilada e as sementes alocadas em uma única camada uniforme sobre tela metálica. As caixas foram mantidas em câmera de envelhecimento em temperatura de $43{ }^{\circ} \mathrm{C}$ durante 48 horas (FANAN et al., 2006). Após período de envelhecimento foi realizado 0 teste de germinação conforme descrito anteriormente computando-se a porcentagem de plântulas normais no quarto dia após a semeadura.

Teste de tetrazólio: foram utilizadas para o teste quatro repetições de 50 sementes, pré-umedecidas por embebição em água a $20{ }^{\circ} \mathrm{C}$ por 18 horas e, posteriormente, preparadas para coloração através de bissecção longitudinal ao longo do embrião com auxílio de lâmina (Figura 1 A e B) (BRASIL, 2009).

Para coloração uma das metades das sementes foram imersas em solução de $0,075 \%$ de tetrazólio a $40{ }^{\circ} \mathrm{C}$ por duas horas, lavadas com água corrente e mantidas submersas até o momento da avaliação (CARVALHO et al., 2013). O excesso de água foi removido com papel toalha, em seguida dispostas sobre vidro de scanner de mesa HP Deskjet F4180 (Figura 1 C) e digitalizadas com definição de 2400 pontos por polegada quadrada (dpi), com imagens armazenadas em arquivo JPG.

Figura 1. Detalhes do corte das sementes de trigo em bissecção longitudinal ao longo do embrião e do endosperma ( $\mathrm{A}$ e $\mathrm{B}$ ); posicionamento das sementes em scanner de mesa para digitalização do teste de tetrazólio (C).
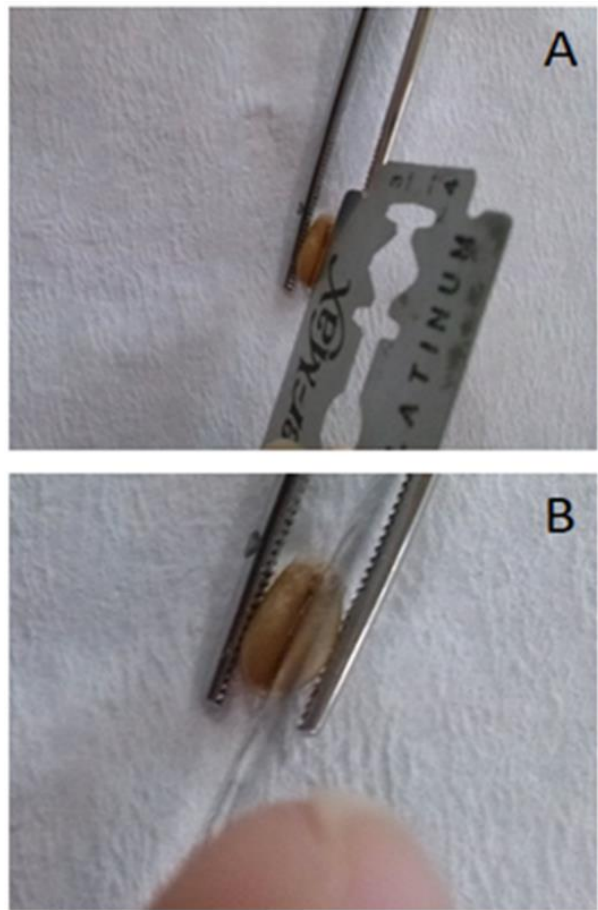

B

As imagens digitalizadas foram avaliadas com ampliação de 17x (Figura 2) e brilho de tela do monitor em $70 \%$. As sementes foram classificadas em quatro classes de vigor de acordo com Carvalho et al. (2012), sendo a classe I: semente viável e vigorosa, classe II: semente viável, classe III: semente não viável e classe IV: semente morta. Sementes viáveis apresentam coloração rosa brilhante, superficial, uniforme e sem lesões embrionárias, ou pequenas lesões em

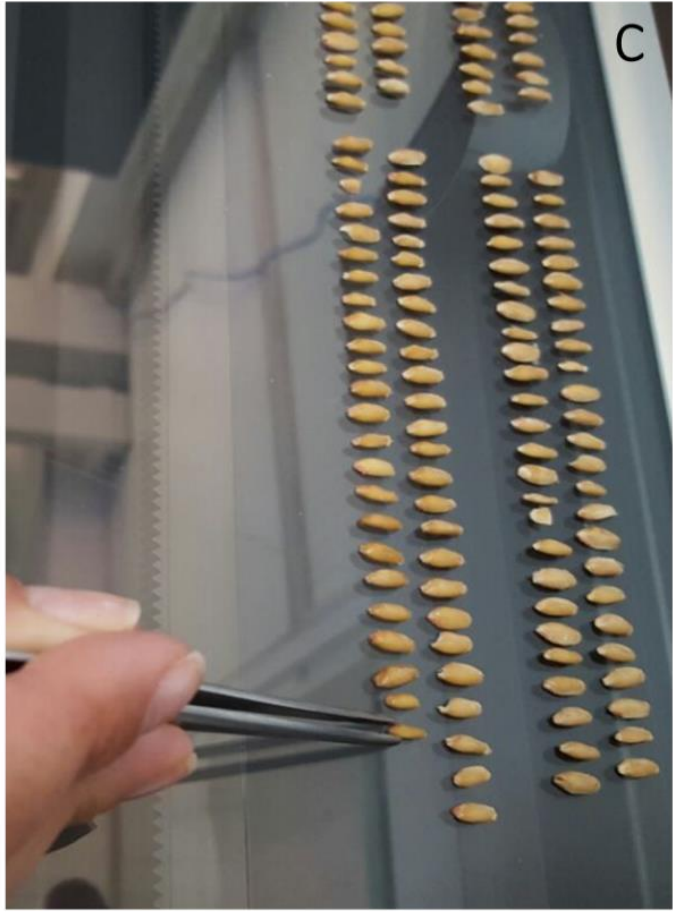

tecidos não vitais, estas são capazes de produzir plântulas normais no teste de germinação. Já as sementes não viáveis apresentam colorações não definidas ou com estruturas essenciais flácidas ou não coloridas, sementes com desenvolvimento anormal do embrião ou de outra estrutura essencial também são consideradas como não viáveis, independentemente se coloridas ou não (BRASIL, 2009). Sementes mortas não apresentam coloração dos tecidos. 
Figura 2. Forma de observação e zoom utilizado nas imagens digitalizadas para avaliação do teste de tetrazólio em sementes de trigo.

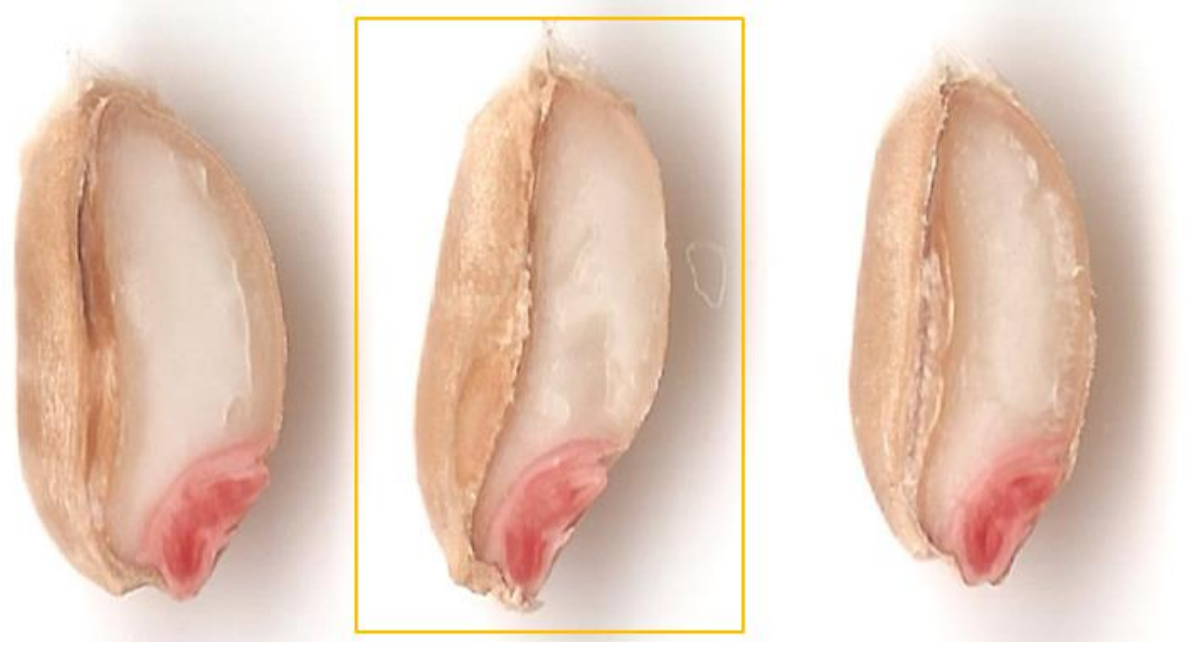

A percentagem de sementes vigorosas pelo teste de tetrazólio (TZVg) foi calculada em função da classe I e a percentagem das sementes viáveis foi obtida pela soma das classes I e II $(T Z V b)$ em relação ao total de sementes testadas. Além dessas duas variáveis, TZVg e TZVb, calculou-se uma terceira, proveniente do produto de ambas, em nível de repetições, gerando a TZVgb, ou seja, produto da viabilidade e vigor, obtido pela expressão:

$$
\operatorname{TZVgb}(\%)=[(T Z V g / 100)(T Z V b / 100)] 100
$$

$=[(\mathrm{TZVg})(\mathrm{TZVb})] / 100$

$O$ experimento seguiu o delineamento inteiramente casualizado e os dados foram submetidos à análise de variância a $1 \%$ de probabilidade de erro, com as médias comparadas pelo teste Scott-Knott, a $5 \%$ de significância. Também foi realizada análise dos coeficientes de correlação simples ( $r$ ), entre os resultados dos testes de tetrazólio e demais testes, verificando a significância dos valores de $r$ pelo teste $\mathrm{t}$, em nível de $5 \%$ de significância, utilizando o software Genes (CRUZ, 1997).

Os adjetivos para descrever a magnitude das correlações foram empregados de acordo com Davis (1971), onde os valores absolutos de $r=0,01$ a 0,09 são correlações negligenciáveis, $r=0,10$ a 0,29 são baixas, $r=$ 0,30 , a 0,49 são moderadas, $r=0,50$ a 0,69 são substanciais, $r=0,70$ a 0,99 são muito altas e $r=$ 1,0 é considerada correlação perfeita.

Os dados da relação entre as porcentagens de germinação e viabilidade pelo teste de tetrazólio foram submetidos a análise de quadrante através de gráfico de dispersão. 0 mesmo foi realizado para a porcentagem de germinação e o produto da viabilidade e vigor pelo teste de tetrazólio (TZ), e para a frequência dos lotes no grupo "a" através do teste SkottKnott nas médias das 13 variáveis analisadas.

\section{Resultados e discussão}

A germinação (Tabela 1 ) classificou os lotes $1,2,6,8,13,17$ e 22 com alta viabilidade, acima de $96 \%$, já os lotes $7,10,15,16$ e 21 apresentaram valores abaixo dos padrões de $80 \%$ de germinação estabelecidos para comercialização de sementes de trigo no Brasil (BRASIL, 2005). Assim como observado para germinação, os lotes 7 e 15 apresentaram menor desempenho, com menor porcentagem de plântulas normais. Para fins propostos na pesquisa, a presença de lotes com níveis contrastantes de viabilidade é fundamental, permitindo identificar a real qualidade do lote, independente de baixa ou alta qualidade (CARVALHO et al., 2019).

O mesmo foi observado no índice de velocidade de germinação, onde os lotes 7 e 15 apresentaram 50\% menos sementes germinadas por dia, podendo apresentar desempenho inferior a campo devido à baixa velocidade de germinação, como apontado por Höfs et al. (2004) em estudo com sementes de arroz e por Ludwig et al. (2009) em sementes de milho, em que a utilização de sementes com menor qualidade fisiológica resultaram em atraso da emergência de plântulas e aumento da desuniformidade de emergência. 
Tabela 1. Comparação dos resultados do teste de germinação, primeira contagem de germinação, índice de velocidade de germinação (IVG) e envelhecimento acelerado (EA) entre 22 lotes de sementes de trigo.

\begin{tabular}{|c|c|c|c|c|}
\hline Lotes & Germinação (\%) & Primeira contagem (\%) & IVG & EA (\%) \\
\hline 1 & 99 a & $91 \mathrm{a}$ & 12,15 a & $69 \mathrm{~b}$ \\
\hline 2 & $98 \mathrm{a}$ & $96 a$ & $12,40 \mathrm{a}$ & $80 \mathrm{a}$ \\
\hline 3 & $93 \mathrm{~b}$ & $79 \mathrm{~b}$ & $11,09 \mathrm{~b}$ & $44 d$ \\
\hline 4 & $93 \mathrm{~b}$ & $92 \mathrm{a}$ & 11,88 a & $62 c$ \\
\hline 5 & $89 \mathrm{~b}$ & $77 \mathrm{~b}$ & $11,20 b$ & $40 d$ \\
\hline 6 & $97 \mathrm{a}$ & $87 a$ & 11,89 a & $59 c$ \\
\hline 7 & 59 e & $27 \mathrm{~g}$ & $6,29 f$ & $1 \mathrm{~g}$ \\
\hline 8 & $97 \mathrm{a}$ & $76 \mathrm{~b}$ & $11,54 \mathrm{~b}$ & $25 \mathrm{e}$ \\
\hline 9 & $85 c$ & $69 c$ & $10,10 \mathrm{c}$ & $24 \mathrm{e}$ \\
\hline 10 & $75 d$ & $71 \mathrm{c}$ & $9,24 d$ & $5 \mathrm{~g}$ \\
\hline 11 & $91 b$ & $46 \mathrm{e}$ & $10,12 \mathrm{c}$ & $57 c$ \\
\hline 12 & $92 \mathrm{~b}$ & $84 \mathrm{a}$ & $11,32 \mathrm{~b}$ & $67 \mathrm{~b}$ \\
\hline 13 & $96 a$ & $91 \mathrm{a}$ & 11,88 a & $69 \mathrm{~b}$ \\
\hline 14 & $92 \mathrm{~b}$ & $61 \mathrm{~d}$ & $10,34 \mathrm{c}$ & $42 \mathrm{~d}$ \\
\hline 15 & $61 \mathrm{e}$ & $28 \mathrm{~g}$ & $6,68 \mathrm{f}$ & $15 f$ \\
\hline 16 & $74 \mathrm{~d}$ & $39 \mathrm{f}$ & $8,02 \mathrm{e}$ & $2 \mathrm{~g}$ \\
\hline 17 & $98 \mathrm{a}$ & $86 a$ & 11,87 a & $4 \mathrm{~g}$ \\
\hline 18 & $90 \mathrm{~b}$ & $83 \mathrm{a}$ & $11,11 \mathrm{~b}$ & $61 c$ \\
\hline 19 & $85 c$ & $69 c$ & $10,11 \mathrm{c}$ & $32 \mathrm{e}$ \\
\hline 20 & $85 c$ & $58 \mathrm{~d}$ & $9,79 \mathrm{c}$ & $15 \mathrm{f}$ \\
\hline 21 & $76 d$ & $55 d$ & $8,77 \mathrm{~d}$ & $1 \mathrm{~g}$ \\
\hline 22 & $97 \mathrm{a}$ & $91 \mathrm{a}$ & 11,93 a & $19 \mathrm{f}$ \\
\hline Média & 87,16 & 70,50 & 10,44 & 35,68 \\
\hline CV \% & 5,0 & 8,6 & 5,0 & 15,0 \\
\hline
\end{tabular}

Médias seguidas pelas mesmas letras minúsculas na coluna constituem grupo estatisticamente homogêneo pelo teste de Skott-Knott a $5 \%$ de probabilidade.

Lotes com menor IVG tendem a apresentar desempenho inferior a campo devido à baixa velocidade de germinação, como apontado por Höfs et al. (2004) em estudo com sementes de arroz e por Ludwig et al. (2009) em sementes de milho, em que a utilização de sementes com menor qualidade fisiológica resultou em atraso da emergência de plântulas e aumento na desuniformidade de emergência.

No teste de envelhecimento acelerado (Tabela 1) apenas o lote 2 apresentou vigor elevado. Quanto aos valores próximos à zero, estes são explicados pela ocorrência de contaminação das amostras após condicionamento, devido à condição de alta umidade e temperaturas, utilizadas para condução do teste, ser favoráveis para desenvolvimento fúngico, podendo ser controlada com o uso de solução saturada de sais (COSTA et al., 2008; LOPES et al., 2009).

Os lotes 2, 5, 6 e 13 apresentaram maior comprimento de raiz e plântula total (Tabela 2). Para as variáveis de matéria seca apenas a raiz foi eficiente na identificação de lotes intermediários devido à classificação em três grupos de vigor. 
Tabela 2. Comparação dos resultados dos testes de comprimento de plântula da parte aérea (CPA), raiz $(C P R)$, total (CPT) e de matéria seca da parte aérea (MSA), raiz (MSR) e total (MST) entre 22 lotes de sementes de trigo.

\begin{tabular}{lllllll}
\hline Lotes & CPA $(\mathbf{c m})$ & CPR $(\mathbf{c m})$ & CPT $(\mathbf{c m})$ & MAS (mg) & MSR (mg) & MST (mg) \\
\hline 1 & $5,89 \mathrm{~d}$ & $13,95 \mathrm{~b}$ & $19,84 \mathrm{c}$ & $4,58 \mathrm{~b}$ & $6,68 \mathrm{a}$ & $26 \mathrm{a}$ \\
2 & $6,19 \mathrm{~d}$ & $15,01 \mathrm{a}$ & $21,20 \mathrm{~b}$ & $4,70 \mathrm{~b}$ & $5,40 \mathrm{~b}$ & $10 \mathrm{~b}$ \\
3 & $6,84 \mathrm{c}$ & $13,18 \mathrm{~b}$ & $20,02 \mathrm{c}$ & $5,03 \mathrm{a}$ & $5,45 \mathrm{~b}$ & $48 \mathrm{~b}$ \\
4 & $7,51 \mathrm{~b}$ & $13,91 \mathrm{~b}$ & $21,42 \mathrm{~b}$ & $5,53 \mathrm{a}$ & $5,83 \mathrm{~b}$ & $35 \mathrm{a}$ \\
5 & $8,59 \mathrm{a}$ & $16,61 \mathrm{a}$ & $25,20 \mathrm{a}$ & $6,10 \mathrm{a}$ & $6,88 \mathrm{a}$ & $38 \mathrm{a}$ \\
6 & $6,75 \mathrm{c}$ & $15,89 \mathrm{a}$ & $22,64 \mathrm{~b}$ & $5,25 \mathrm{a}$ & $5,58 \mathrm{~b}$ & $33 \mathrm{a}$ \\
7 & $5,41 \mathrm{e}$ & $8,98 \mathrm{~d}$ & $14,38 \mathrm{e}$ & $5,45 \mathrm{a}$ & $4,85 \mathrm{c}$ & $30 \mathrm{~b}$ \\
8 & $5,26 \mathrm{e}$ & $13,90 \mathrm{~b}$ & $19,17 \mathrm{c}$ & $4,08 \mathrm{~b}$ & $5,65 \mathrm{~b}$ & $3 \mathrm{~b}$ \\
9 & $6,77 \mathrm{c}$ & $11,13 \mathrm{c}$ & $17,90 \mathrm{~d}$ & $5,50 \mathrm{a}$ & $5,10 \mathrm{c}$ & $50 \mathrm{~b}$ \\
10 & $6,20 \mathrm{~d}$ & $13,19 \mathrm{~b}$ & $19,39 \mathrm{c}$ & $5,28 \mathrm{a}$ & $6,65 \mathrm{a}$ & $33 \mathrm{a}$ \\
11 & $5,59 \mathrm{e}$ & $12,37 \mathrm{~b}$ & $17,97 \mathrm{~d}$ & $4,43 \mathrm{~b}$ & $4,68 \mathrm{c}$ & $3 \mathrm{~b}$ \\
12 & $6,51 \mathrm{c}$ & $14,11 \mathrm{~b}$ & $20,62 \mathrm{c}$ & $3,68 \mathrm{~b}$ & $5,85 \mathrm{~b}$ & $3 \mathrm{~b}$ \\
13 & $7,60 \mathrm{~b}$ & $16,18 \mathrm{a}$ & $23,78 \mathrm{a}$ & $5,68 \mathrm{a}$ & $6,53 \mathrm{a}$ & $20 \mathrm{a}$ \\
14 & $5,64 \mathrm{e}$ & $9,48 \mathrm{~d}$ & $15,12 \mathrm{e}$ & $4,08 \mathrm{~b}$ & $4,23 \mathrm{c}$ & $\mathrm{J} \mathrm{b}$ \\
15 & $4,02 \mathrm{~g}$ & $8,74 \mathrm{~d}$ & $12,76 \mathrm{e}$ & $3,58 \mathrm{~b}$ & $3,58 \mathrm{c}$ & $5 \mathrm{~b}$ \\
16 & $4,80 \mathrm{f}$ & $8,98 \mathrm{~d}$ & $13,78 \mathrm{e}$ & $4,55 \mathrm{~b}$ & $4,55 \mathrm{c}$ & $\mathrm{J} \mathrm{b}$ \\
17 & $5,74 \mathrm{e}$ & $12,66 \mathrm{~b}$ & $18,40 \mathrm{~d}$ & $6,10 \mathrm{a}$ & $6,10 \mathrm{~b}$ & $20 \mathrm{a}$ \\
18 & $7,00 \mathrm{c}$ & $14,04 \mathrm{~b}$ & $21,03 \mathrm{~b}$ & $4,88 \mathrm{~b}$ & $4,85 \mathrm{c}$ & $3 \mathrm{~b}$ \\
19 & $5,46 \mathrm{e}$ & $13,77 \mathrm{~b}$ & $19,23 \mathrm{c}$ & $4,43 \mathrm{~b}$ & $5,35 \mathrm{~b}$ & $3 \mathrm{~b}$ \\
20 & $5,37 \mathrm{e}$ & $12,35 \mathrm{~b}$ & $17,72 \mathrm{~d}$ & $5,03 \mathrm{a}$ & $5,08 \mathrm{c}$ & $10 \mathrm{~b}$ \\
21 & $6,29 \mathrm{~d}$ & $11,73 \mathrm{c}$ & $18,02 \mathrm{~d}$ & $4,65 \mathrm{~b}$ & $4,70 \mathrm{c}$ & $5 \mathrm{~b}$ \\
22 & $6,10 \mathrm{~d}$ & $13,58 \mathrm{~b}$ & $19,68 \mathrm{c}$ & $4,55 \mathrm{~b}$ & $5,65 \mathrm{~b}$ & $20 \mathrm{~b}$ \\
\hline Média & 6,16 & 12,90 & 19,06 & 4,87 & 5,42 & 28 \\
CV\% & 5,5 & 8,6 & 6,8 & 17,4 & 14,1 & $\mathrm{~J}$ \\
\hline
\end{tabular}

Médias seguidas pelas mesmas letras minúsculas na coluna constituem grupo estatisticamente homogêneo pelo teste de Skott-Knott a $5 \%$ de probabilidade.

Na Tabela 3 estão apresentados os resultados do teste de tetrazólio, que agrupou os lotes em três níveis de vigor e viabilidade $(a, b$ e c), classificando os lotes com alto vigor, acima de $87 \%$ e os lotes 7 e 16 com baixo vigor. 
Tabela 3. Comparação dos resultados do teste de tetrazólio para vigor (Vg \%), viabilidade (Vb \%) e seu produto ( $\mathrm{Vg} . \mathrm{Vb} \%$ ) avaliados por análise de imagens digitalizadas, germinação padrão (\%), índice de velocidade de germinação (IVG \%) e frequência da classificação dos lotes de trigo no grupo "a" em 13 variáveis analisadas.

\begin{tabular}{|c|c|c|c|c|c|c|c|}
\hline \multirow{2}{*}{ Lotes } & \multicolumn{3}{|c|}{ Tetrazólio (\%) } & \multirow{2}{*}{\multicolumn{2}{|c|}{$\begin{array}{l}\text { Germinação ; } \\
\text { (\%) }\end{array}$}} & \multicolumn{2}{|c|}{ "requência no grupo"a" } \\
\hline & $\mathbf{V g}$ & $\mathrm{Vb}$ & (Vg).(Vb) & & & n. & (\%) \\
\hline 1 & $96 a$ & $97 \mathrm{a}$ & $93 a$ & 99 a & $L 2,15 \mathrm{a}$ & 8 & 61,5 \\
\hline 2 & $96 \mathrm{a}$ & $96 a$ & $92 \mathrm{a}$ & $98 \mathrm{a}$ & $\mathrm{L} 2,40 \mathrm{a}$ & 8 & 61,5 \\
\hline 3 & $91 \mathrm{a}$ & $92 \mathrm{a}$ & $84 \mathrm{a}$ & $93 \mathrm{~b}$ & $L 1,09 \mathrm{~b}$ & 4 & 30,8 \\
\hline 4 & $95 \mathrm{a}$ & $95 \mathrm{a}$ & $91 \mathrm{a}$ & $93 \mathrm{~b}$ & $\lfloor 1,88 \mathrm{a}$ & 7 & 53,8 \\
\hline 5 & $87 a$ & $88 \mathrm{~b}$ & $77 \mathrm{~b}$ & $89 b$ & $\lfloor 1,20 \mathrm{~b}$ & 7 & 53,8 \\
\hline 6 & $92 \mathrm{a}$ & $93 a$ & $86 a$ & $97 a$ & $\lfloor 1,89$ a & 9 & 69,2 \\
\hline 7 & $68 c$ & $80 c$ & $54 \mathrm{c}$ & 59 e & $j, 29 f$ & 1 & 7,7 \\
\hline 8 & $97 a$ & $98 \mathrm{a}$ & $95 \mathrm{a}$ & $97 a$ & $\lfloor 1,54 \mathrm{~b}$ & 4 & 30,8 \\
\hline 9 & $83 \mathrm{~b}$ & $87 \mathrm{~b}$ & $73 b$ & $85 c$ & $L 0,10 \mathrm{c}$ & 1 & 7,7 \\
\hline 10 & $81 b$ & $84 \mathrm{~b}$ & $68 \mathrm{~b}$ & $75 d$ & $3,24 \mathrm{~d}$ & 3 & 23,1 \\
\hline 11 & $89 a$ & $94 \mathrm{a}$ & $84 \mathrm{a}$ & $91 \mathrm{~b}$ & $10,12 \mathrm{c}$ & 3 & 23,1 \\
\hline 12 & 91 a & $95 \mathrm{a}$ & $87 a$ & $92 \mathrm{~b}$ & $\lfloor 1,32 b$ & 4 & 30,8 \\
\hline 13 & $93 a$ & $95 \mathrm{a}$ & $89 a$ & 96 a & $\lfloor 1,88 \mathrm{a}$ & 11 & 84,6 \\
\hline 14 & $92 \mathrm{a}$ & $95 \mathrm{a}$ & $87 \mathrm{a}$ & $92 b$ & $10,34 \mathrm{c}$ & 3 & 23,1 \\
\hline 15 & $78 \mathrm{~b}$ & $80 \mathrm{c}$ & $62 c$ & $61 \mathrm{e}$ & $j, 68 \mathrm{f}$ & 0 & 0,0 \\
\hline 16 & $72 \mathrm{c}$ & $91 \mathrm{a}$ & $66 \mathrm{~b}$ & $74 \mathrm{~d}$ & $3,02 \mathrm{e}$ & 1 & 7,7 \\
\hline 17 & $96 a$ & $96 a$ & $91 \mathrm{a}$ & $98 \mathrm{a}$ & $\lfloor 1,87$ a & 8 & 61,5 \\
\hline 18 & $94 \mathrm{a}$ & $94 \mathrm{a}$ & $89 a$ & $90 \mathrm{~b}$ & $\lfloor 1,11 b$ & 4 & 30,8 \\
\hline 19 & $95 \mathrm{a}$ & $95 \mathrm{a}$ & $90 \mathrm{a}$ & $85 c$ & $\llcorner 0,11 \mathrm{c}$ & 3 & 23,1 \\
\hline 20 & $91 \mathrm{a}$ & $96 a$ & $87 a$ & $85 c$ & $3,79 \mathrm{c}$ & 4 & 30,8 \\
\hline 21 & $78 \mathrm{~b}$ & $86 \mathrm{~b}$ & $67 \mathrm{~b}$ & $76 d$ & $3,77 \mathrm{~d}$ & 0 & 0,0 \\
\hline 22 & $96 a$ & $98 \mathrm{a}$ & $94 \mathrm{a}$ & $97 a$ & $\lfloor 1,93$ a & 6 & 46,2 \\
\hline Média & 88,7 & 91,9 & 81,9 & 87,16 & 44 & 4,5 & 34,6 \\
\hline CV\% & 5,0 & 4,0 & 8,2 & 5,0 & & - & - \\
\hline
\end{tabular}

Médias seguidas pelas mesmas letras minúsculas na coluna constituem grupo estatisticamente homogêneo pelo teste de Skott-Knott a $5 \%$ de probabilidade.

A interpretação do teste por análise de imagens digitalizadas permitiu avaliação nítida das partes vitais do embrião, facilitando a interpretação. As imagens escaneadas permitiram identificação de lotes com sementes menos vigorosas, não interferindo na caracterização de coloração cinza a branco leitoso, própria de tecidos não vivos (Figura 3). 0 que corrobora com os resultados obtidos por Custódio et al. (2012) com interpretação de tetrazólio em sementes de Brachiaria brizantha por meio de análise de imagens digitalizadas, evidenciando a eficiência da interpretação equivalente ao emprego de estéreo microscópio.

Através da análise das imagens digitalizadas (Figura 13) também foi possível observar a ocorrência de sementes viáveis e vigorosas, sem presença de danos no embrião, de coloração rosa uniforme (Figura $A$ ) ou pequenas áreas, pontos deteriorados ou tecidos mortos nas extremidades do escutelo, sem atingir a região vital (Figura B). Sementes viáveis com danos na radícula, mas com a região do mesocótilo ilesa (Figuras C, D, H). Sementes não viáveis com áreas descoloridas sobre a plúmula e a região do coleóptilo e radícula (Figura $\mathrm{F} \mathrm{e} \mathrm{G}$ ), ou com áreas descoloridas sobre a região da radícula, mesocótilo e região central do escutelo $(H)$, e sementes mortas apresentando embrião totalmente acinzentado (I e J) (CARVALHO et al., 2012). 
Figura 3. Imagens digitalizadas do teste de tetrazólio em sementes de trigo: classe I, semente viável e vigorosa (A e B); classe II, semente viável (C, D e E); classe III, semente não viável (F, G e H) e classe IV, semente morta (l e J).
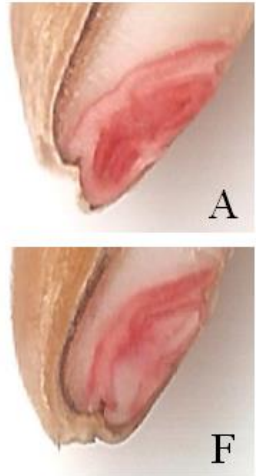
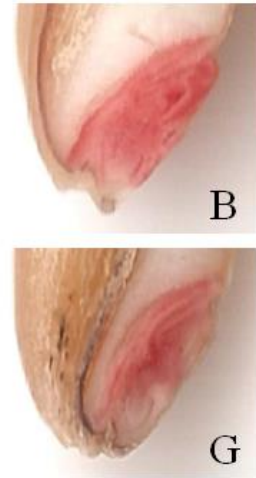

$\mathrm{C}$

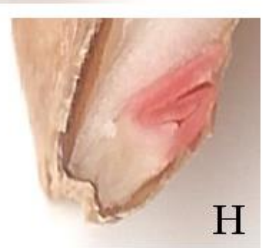

$\mathrm{D}$
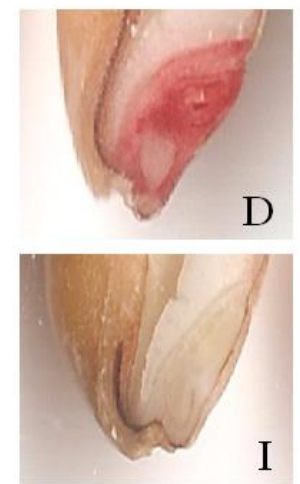

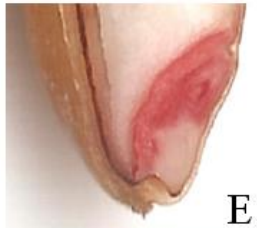

E

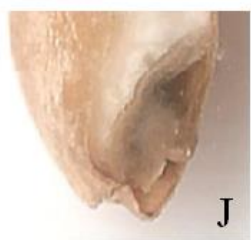

Para níveis intermediários de vigor, no teste de tetrazólio, não ocorreu subdivisões entre os lotes (Tabela 3) o que pode ser explicado pela dificuldade na avaliação de diferenças entre os tons de rosa claro, característico de tecidos viáveis, e vermelho carmim de tecidos em deterioração. Sendo esta, uma limitação da interpretação de imagens digitais, devido à perspectiva de cor ser dependente de vários fatores como resolução, memória, capacidade ótica e iluminação. Assim, apesar da importância comercial associada à definição linear de cores, não existe linearidade de cores para interpretação, uma vez que é realizada à olho humano e esta ser amplamente influenciada (FORSYTH; PONCE, 2003).

A composição por pixels das imagens digitais é outro fator limitante para a técnica, podendo haver perdas de qualidade das imagens ao se aplicar zoom maior que o limite gráfico. Para maior detalhamento, o computador redesenha os pixels com base na fatoração da imagem, prejudicando o julgamento em relação à matriz de cores (GONZALEZ; WOODS, 2009).
Assim, a padronização é limitada a diversos fatores, havendo a necessidade de se utilizar equipamentos com modelo cromático capaz de envolver as diversas variações perceptíveis à visão humana.

Quanto aos valores dos coeficientes de correlação (Tabela 4), estes indicaram alta correlação entre o teste de germinação e os testes de primeira contagem, índice de velocidade de germinação, comprimento de raiz, vigor e viabilidade pelo teste de tetrazólio com valor positivo e significativo para seu produto (G $\times \mathrm{TZVgb}=0,93$ ).

Correlações elevadas com a germinação sugerem eficiência dos testes para determinação de vigor. Assim, os resultados do teste de tetrazólio, tanto para determinação do vigor como para viabilidade, indicam eficiência da interpretação por meio de análise de imagens digitalizadas. Carvalho et al. (2013) obtiveram resultados semelhantes, a cima de 0,90 de correlação, na determinação da melhor metodologia para o teste de tetrazólio em sementes de trigo. 
Tabela 4. Resultados de correlação ( $r$ ) entre os testes de germinação $(G)$, primeira contagem da germinação $(\mathrm{PC})$, índice de velocidade de germinação (IVG), comprimento de parte aérea de plântulas (CPA), comprimento de raiz (CPR), comprimento total (CPT), matéria seca de parte aérea (MSA), matéria seca de raiz (MSR), matéria seca total (MST), envelhecimento acelerado (EA), tetrazólio vigor (Tzvg), tetrazólio viabilidade (Tzvb) e seu produto (Tzvgb).

\begin{tabular}{llllllllllllll}
\hline \multicolumn{2}{c}{ PC } & IVG & EA & CPA & CPR & CPT & MSA & MSR & MST & Tzvg & Tzvb & TZVgb \\
\hline G & $0,86^{* *}$ & $0,97^{* *}$ & $0,65^{* *}$ & $0,46^{*}$ & $0,71^{* *}$ & $0,67^{* *}$ & $0,13^{\text {ns }}$ & $0,51^{*}$ & $0,39^{\text {ns }}$ & $0,91^{* *}$ & $0,88^{* *}$ & $0,93^{* *}$ \\
PC & - & $0,95^{* *}$ & $0,61^{* *}$ & $0,63^{* *}$ & $0,83^{* *}$ & $0,82^{* *}$ & $0,29^{* *}$ & $0,71^{* *}$ & $0,59^{* *}$ & $0,82^{* *}$ & $0,68^{* *}$ & $0,79^{* *}$ \\
IVG & - & - & $0,67^{* *}$ & $0,57^{* *}$ & $0,81^{* *}$ & $0,78^{* *}$ & $0,21^{\text {ns }}$ & $0,62^{* *}$ & $0,50^{*}$ & $0,90^{* *}$ & $0,82^{* *}$ & $0,90^{* *}$ \\
EA & - & - & - & $0,48^{*}$ & $0,62^{* *}$ & $0,62^{* *}$ & $-0,08^{\text {ns }}$ & $0,28^{\text {ns }}$ & $0,13^{\text {ns }}$ & $0,62^{* *}$ & $0,52^{*}$ & $0,25^{\text {ns }}$ \\
CPA & - & - & - & - & $0,72^{* *}$ & $0,86^{* *}$ & $0,62^{* *}$ & $0,63^{* *}$ & $0,71^{* *}$ & $0,30^{\text {ns }}$ & $0,15^{\text {ns }}$ & $0,64^{* *}$ \\
CPR & - & - & - & - & - & $0,97^{* *}$ & $0,35^{\text {ns }}$ & $0,76^{* *}$ & $0,65^{* *}$ & $0,67^{* *}$ & $0,50^{*}$ & $0,55^{* *}$ \\
CPT & - & - & - & - & - & - & $0,46^{*}$ & $0,77^{* *}$ & $0,72^{* *}$ & $0,60^{* *}$ & $0,42^{*}$ & $0,05^{\text {ns }}$ \\
MAS & - & - & - & - & - & - & - & $0,55^{* *}$ & $0,85^{* *}$ & $-0,01^{\text {ns }}$ & $-0,10^{\text {ns }}$ & $0,39^{\text {ns }}$ \\
MSR & - & - & - & - & - & - & - & - & $0,90^{\text {ns }}$ & $0,42^{\text {ns }}$ & $0,31^{\text {ns }}$ & $0,22^{\text {ns }}$ \\
MST & - & - & - & - & - & - & - & - & - & $0,25^{\text {ns }}$ & $0,14^{\text {ns }}$ & $0,61^{* *}$ \\
Tzvg & - & - & - & - & - & - & - & - & - & - & $0,87^{* *}$ & $0,98^{* *}$ \\
Tzvb & - & - & - & - & - & - & - & - & - & - & - & $0,94^{* *}$ \\
\hline
\end{tabular}

*significativo pelo teste $\mathrm{t}$ a $5 \%$ de probabilidade; ${ }^{* *}$ significativo pelo teste $\mathrm{t}$ a $1 \%$ de probabilidade; ns não significativo pelo teste $t$.

O teste de tetrazólio também apresentou alta correlação com os demais testes de vigor analisados, como primeira contagem de germinação e IVG, ambos apresentando correlação positiva com o teste de germinação, o que corrobora a eficiência da metodologia empregada para o teste de tetrazólio na determinação de vigor.

Apesar das limitações, o teste de tetrazólio com interpretação através de análise de imagens digitalizadas é promissor para a utilização em programas de controle de qualidade, permitindo ampliação e observação precisa das estruturas internas do embrião. A técnica também tem por vantagens possibilitar o arquivamento das imagens e avaliação em dias posteriores à obtenção dos resultados, criação de banco de imagens como base para leituras computadorizadas e compartilhamento.

A Figura 4 evidencia a relação, praticamente linear, entre viabilidade e vigor estimadas pelo teste de tetrazólio, o que também é confirmado pela correlação positiva e significativa entre essas duas variáveis, alcançando o valor de 0,87 (Figura 5).

Figura 4. Gráfico de quadrantes da relação (em \%) entre viabilidade e vigor pelo teste de tetrazólio (TZ) em 22 lotes de sementes de trigo.

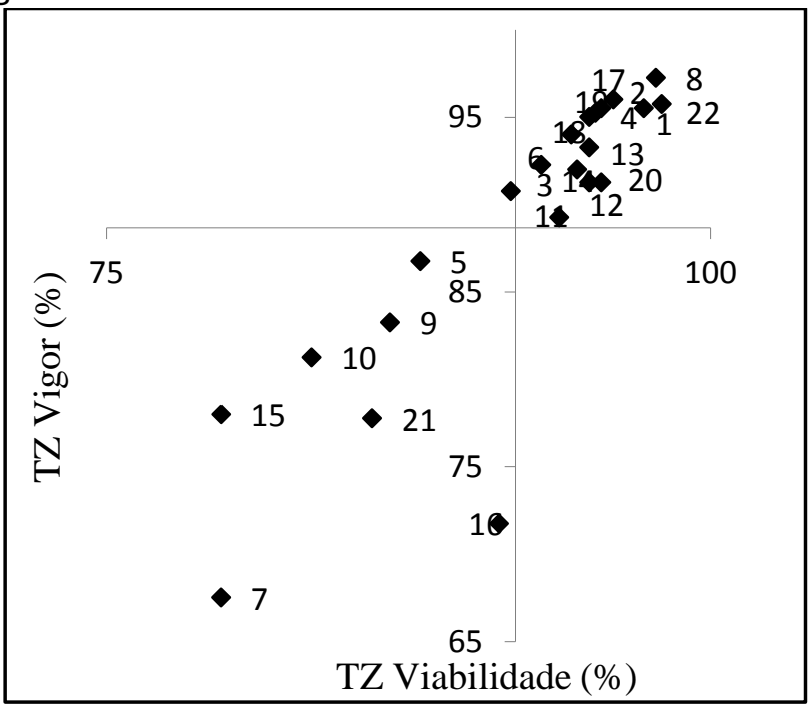


A relação entre germinação e o produto da viabilidade e vigor pelo teste de tetrazólio é linear e apresenta alto coeficiente de determinação $\left(R^{2}\right)$ (Figura 5 a), em torno de 0,89 , indicando confiabilidade da equação. Lotes de alto potencial fisiológico apresentam valores acima de $80 \%$ tanto para germinação quanto para a variável do produto entre viabilidade e vigor pelo teste de tetrazólio.

Figura 5. Gráfico de quadrantes entre o produto das variáveis vigor e viabilidade (TZVgb) e germinação (a) e pela frequência no grupo "a" (b) através do teste Skott-Knott em 13 variáveis analisadas, relativas a 22 lotes de sementes de trigo.

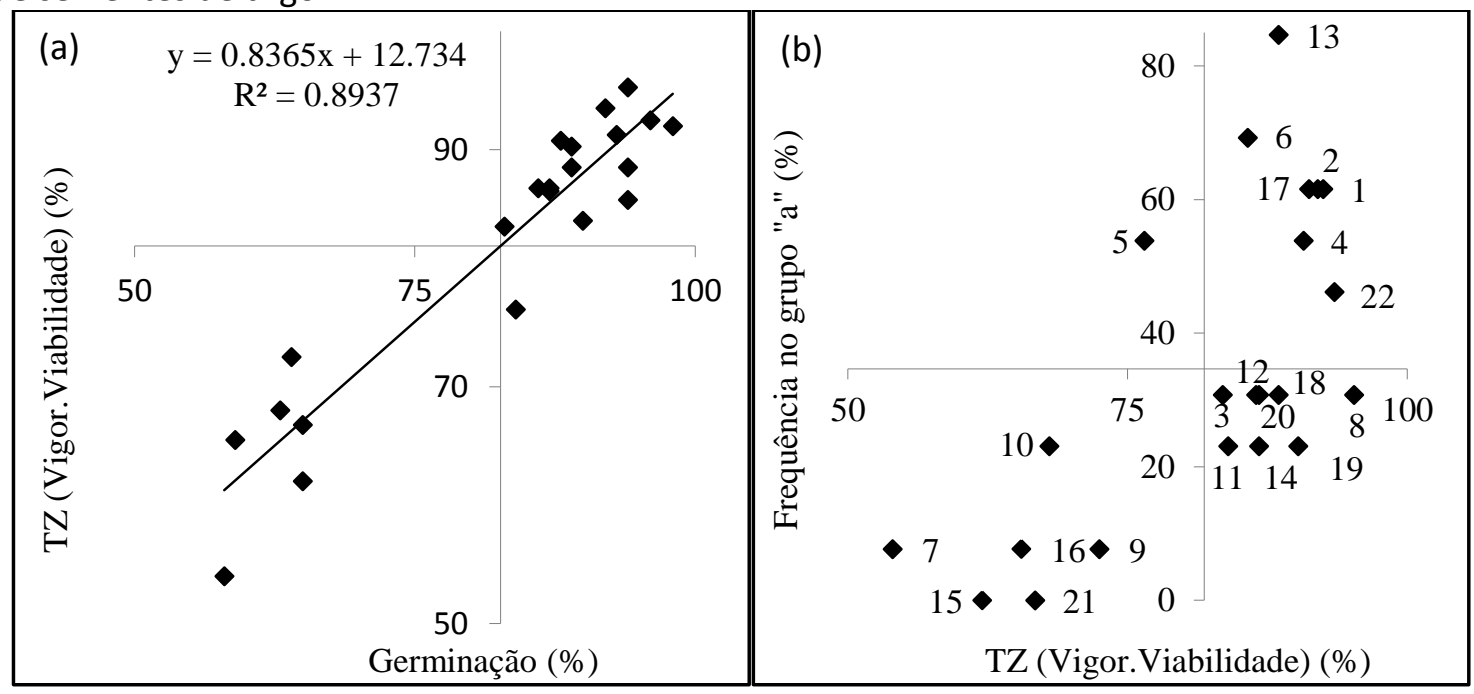

A Figura 5 (b) resume o desempenho dos 22 lotes de sementes de trigo testados quanto à viabilidade e vigor envolvendo em todas as variáveis analisadas. No quadrante superior direito, encontram-se os lotes com maior vigor e viabilidade e com elevada frequência no agrupamento "a" (os maiores valores) nas diferentes variáveis. Destacam-se os lotes 22,1 , 2,17 e 4 como os de maior viabilidade. No entanto, os lotes viáveis e mais vigorosos foram os $13,6,1$, 2 e 4, que apresentaram frequência no grupo "a" acima de $60 \%$, ou seja, das treze variáveis em pelo menos oito ocuparam a melhor classificação. No quadrante oposto, inferior esquerdo, estão os lotes com pior desempenho com menor viabilidade e vigor, com os lotes $15 \mathrm{e}$ 21 apresentaram zero frequência no grupo "a".

\section{Conclusão}

A avaliação do teste tetrazólio através de interpretação por imagens digitalizadas é eficiente na determinação de vigor e viabilidade de sementes de trigo facilitando ampliação, observação precisa do embrião, arquivamento e compartilhamento de imagens. No entanto, devido às limitações das imagens digitais, principalmente com relação à matiz de cores, necessita ser mais investigado antes de ser indicado para uso generalizado.

\section{Agradecimentos}

O presente trabalho foi realizado com apoio da Coordenação de Aperfeiçoamento de Pessoal de Nível Superior - Brasil (CAPES) - Código de financiamento 001.

\section{Referências}

ABATI, J.; BRZEZINSKI, C. R.; FOLONI, J. S. S.; ZUCARELI, C.; BASSOI, M. C.; HENNING, F. A. Seedling emergence and yield performance of wheat cultivars depending on seed vigor and sowing density. Journal of Seed Science, v. 39, n.1 p.58-65, 2017. https://dx.doi.org/10.1590/2317-1545v39n 1171002.

BRASIL. Ministério da Agricultura, Pecuária e Abastecimento. Instrução Normativa No25, de 16 de dezembro de 2005. Anexo XII - Padrões para produção e comercialização de sementes de trigo e de trigo duro. Brasília: Ministério da Agricultura, 2005. 
BRASIL. Ministério da Agricultura e Reforma Agrária. Coordenação de Laboratório Vegetal. Regras para análise de sementes. Brasília: Ministério da Agricultura, 2009. 395 p.

CARVALHO, I. L.; MENEGHELLO, G. E.; TUNES, L. M.; COSTA, C. J.; SOARES, V. N. Preparo da semente de arroz para execução do teste de tetrazólio. Colloquium Agrariae, v. 15, n.1, p. 5163, 2019. https://dx.doi.org/10.5747/ca.2019.v15.n1.a270.

CARVALHO, T. C.; KRZYZANOWSKI. F. C.; OHLSON. O. C.; PANOBIANCO. M. Improved assessment of wheat seeds vigor. Ciência e Agrotecnologia, v. 36, n. 6, p. 608-614, 2012. https://doi.org/10. 1590/S1413-70542012000600002.

CARVALHO, T. C.; KRZYZANOWSKI, F. C.; OHLSON, O. C.; PANOBIANCO, M. Tetrazolium test adjustment for wheat seeds. Journal of Seed Science, v. 35, n. 3, p. 361-367, 2013. https://doi.org/10.1590/S2317-

15372013000300013.

CARVAlHO, T. C.; NOVEMBRE, A. D. L. C. Comparação de métodos para avaliação de injúrias mecânicas em sementes de duas cultivares de soja. Revista Brasileira de Ciências Agrárias, v.7, n.3, p.372-379, 2012. 10.5039/agraria.v7i3a1075.

COSTA, C. J.; TRZECIAK, M. B.; VILLELA, F. A. Potencial fisiológico de sementes de brássicas com ênfase no teste de envelhecimento acelerado. Horticultura Brasileira, v. 26, n. 2, 2008. http://www. scielo.br/pdf/hb/v26n2/03.pdf.

CUSTÓDIO, C. C.; DAMASCENO, R. L.; MACHADO NETO, N. B. Imagens digitalizadas na interpretação do teste de tetrazólio em sementes de Brachiaria brizantha. Revista Brasileira de Sementes, v. 34, n. 2, p. 334-341, 2012. https://doi.org/10.1590/s010131222012000200020.

CRUZ, C. D. Programa GENES - Aplicativo Computacional em Genética e Estatística. Viçosa: UFV, 1997. $442 \mathrm{p}$.

DAVIS, J. A. Elementary survey analysis. Englewood: Prentice-Hall, 1971. 206 p.
DIAS, M. C. L. L.; BARROS, A. S. R. Metodologia do teste de tetrazólio em sementes de milho. In: KRZYZANOWSKI, F. C.; VIEIRA, R. D., FRANÇA NETO, J. B. Vigor de sementes: conceitos e testes. Londrina: ABRATES, v. 1, 1999. p. 1-10.

FANAN, S.; MEDINA, P. F.; LIMA, T. C.; JULIO MARCOS, J. Avaliação do vigor de sementes de trigo pelos testes de envelhecimento acelerado e de frio. Revista Brasileira de Sementes, v. 28, n. 2, p.152-158, 2006. https://doi.org/10.1590/s010131222006000200021.

FORSYTH, D. A.; PONCE, J. Computer vision: a modern approach. Upper Saddle River: Prentice Hall, 2003. 792 p.

GONZALEZ, R. C.; WOODS, R. Processamento digital de imagens. São Paulo: Saraiva, 2009. 509 p.

HÖFS, A.; SCHUCH, L. O. B.; PESKE, S. T.; BARROS, A. C. S. A. Emergência e crescimento de plântulas de arroz em resposta à qualidade fisiológica de sementes. Revista Brasileira de Sementes, v. 26, n. $1, \quad$ p. $92-97,2004$. https://doi.org/10.1590/S0101$\underline{31222004000100014 .}$

ISTA. Biochemical test for viability: the topographical tetrazolium test. In: International Rules for Seed Testing. Zurich: Bassersdorf, 2008. p. 1-30.

LOPES, R. R.; FRANKE, L. B.; NUNES, F. S. Metodologia alternativa do teste de envelhecimento acelerado para sementes de azevém. Scientia Agraria, v. 10, n. 2, p. 89-94, 2009. https://doi.org/ 10.1590/S010384782011000100006.

LUDWIG, M. P.; SCHUCH, L. A. B.; LUCCA FILHO, O. A.; AVELAR, S. A. G.; MIELEZRSKI, F.; OLIVEIRA, S.; CRIZEL, R. L. Desempenho de sementes e plantas de milho híbrido originadas de lotes de sementes com alta e baixa qualidade fisiológica. Revista Brasileira de Milho e Sorgo, v. 8, n. 1, p. 83-92, 2009. https://doi.org/10.18512/19806477/rbms.v8n01p\%25p

MAGUIRE, J. D. Speeds of germination-aid selection and evolution for seedling emergence and vigor. Crop Science, v.2, n.2. p. 176-177, 
1962.

https://doi.org/10.2135/cropsci1962.0011183X0 $00200020033 x$.

MAIA, L. G. S.; SILVA, C. A.; RAMALHO, M. A. P.; ABREU, A. F. B. Variabilidade genética associada à germinação e vigor de sementes de linhagens de feijoeiro comum. Ciência e Agrotecnologia, v. 35, n. 2, p. 361-367, 2011. https://doi.org/10.1590/S1413-

70542011000200018.

MARCOS FILHO, J.; KIKUTI, A. L. P.; LIMA, L. B. Métodos para avaliação do vigor de sementes de soja, incluindo a análise computadorizada de imagens. Revista Brasileira de Sementes, v. 31, n. 1, p.102-112, 2009.

SILVEIRA, G.; CARVALHO, F. I. F.; OLIVEIRA, A. C.; VALÉRIO, I. P.; BENIN, G.; RIBEIRO, G.; CRESTANI, M.; LUCHE, H. S.; SILVA, J. A. G. Efeito da densidade de semeadura e potencial de afilhamento sobre a adaptabilidade e estabilidade em trigo. Bragantia, v. 69, n.1, p.6370, 2010. https://doi.org/10.1590/S0006$\underline{87052010000100009}$ 